AN ARRANGEMENT FOR CONDUCTING A NCMBER OF I.ABORATORY IOSTIILATIONS IITH STFAM, SIMITIANEOUSLI.

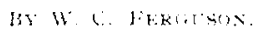

A is an ordinary $\mathrm{B}$ inch iron stean pipe connected with the stean system in the factory and providen with a valve where it enters the laboratory. $B$ is a hrass pipe 1 ? inches in diameter, connected with A and inclining towards $D$, to facilitate the renoral of condensed water.

The tubes $\mathrm{C}$. are about inch in dianeter and are provided with cocks at $\mathrm{l}$.

When distillations are in operation the brass tubes $C$ are connected with glass tubes by means of rubber tubing; the glass

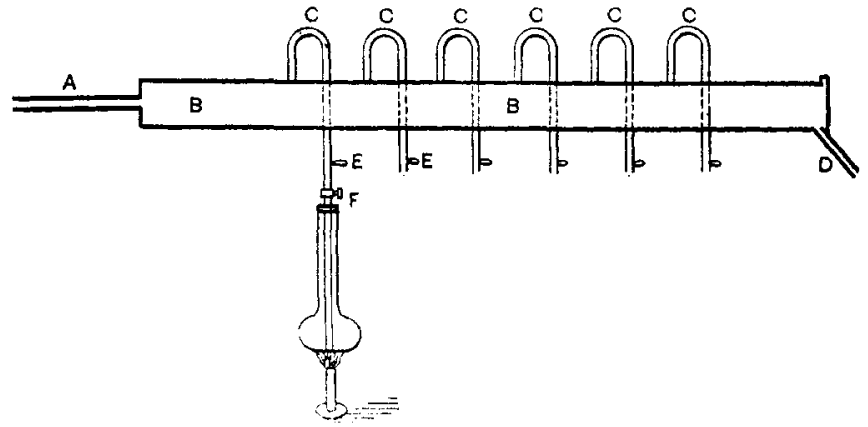

tubes reach nearly to the botton of the distilling flasks and are provided with ground glass stop-cocks at $\mathrm{F}$. D carries off the condensed water from $B$.

The entire apparatus is suspended from the ceiling by stiff iron rods. The condensers are arranged at right angles to, and inmediately underneath $B$. The table is provided with both cold water and waste pipes for the condensers.

$B$ nust be high enough to permit the use of Bunsen burners under the distilling flasks.

Before starting distillations, all of the cocks Ei, must be opened and stean turned on, to blow ont condensed steam; they are then closed, the distilling flasks connected as described above

1 Read December 8,1893 . 
and the cocks $\mathrm{E}$ again opened, taking care to have the ground glass cocks F closed.

During distillation the steam is controlled by the stop-cocks $F$, and the operation is further regulated by the use of Bunsen burners under the distilling flasks. One person can easily attend to six or more distillations at one time.

Experience of more than a year has proved the utility of this arrangement, where many samples involving analysis by distillation, have been presented in a day.

\section{A NEW MUFFLE FOR INCINERATION OF SUGAR.'}

\section{BY H. SCHWEITZER AND E. LUNGwitz.}

$T \mathrm{HE}$ incineration of sugar for the determination of ash is generally carried out in platinum dishes which are placed in a muffle of platinum (Scheibler) or of Russian sheet iron (F. G. Wiechmann) kept at a dull red heat. The platinum muffles to hold two dishes, weigh from sixty to seventy-five grams, and are very expensive apparatus. Moreover it happens very often that in a platinum muffle the last portions of carbon are oxidized with difficulty. Frequently a little higher temperature under the muffle of platinum which is such an extremely good conductor of heat, causes the ash to fuse and the melted salts, including unburnt carbon, form black blotches in the dish. On account of the insufficient draught in the platinum muffe it is then very difficult to accomplish perfect incineration. In such a case, as Tucker says in his manual of sugar analysis, the dish is allowed to cool, one or two drops of sulphuric acid added, and the dish heated cautiously at first to avoid spattering and finally brought to redness for fifteen minutes. Naturally such proceeding causes delay and does not contribute to the exactness of the determination.

The muffles of iron are impracticable for quick commercial work becalse the incineration in them takes much longer time than in those of platinum.

These considerations prompted us to devise an apparatus, better fitted for the incineration of sugar than the muffles mentioned above.

1 Read December S, is93. 